\title{
The bionomics of Anopheles merus (Diptera: Culicidae) along the Kenyan coast
}

\author{
Pamela C Kipyab ${ }^{1,2^{*}}$, Battan M Khaemba ${ }^{2}$, Joseph M Mwangangi ${ }^{1}$ and Charles M Mbogo
}

\begin{abstract}
Background: Anopheles merus, a sibling species of the Anopheles gambiae complex occurs along the East African coast but its biology and role in malaria transmission in this region is poorly understood. We evaluated the blood feeding pattern and the role of this species in malaria transmission in Malindi district, Coastal Kenya.

Methods: Adult mosquitoes were collected indoors by CDC light traps and Pyrethrum Spray Catch and outdoors by CDC light traps. Anopheles females were identified to species by morphological characteristics and sibling species of An. gambiae complex distinguished by rDNA polymerase chain reaction (PCR). Screening for host blood meal sources and presence or absence of Plasmodium falciparum circumsporozoite proteins was achieved by Enzyme Linked Immunosorbent Assays (ELISA).

Results: Anopheles merus comprised $77.8 \%$ of the 387 Anopheles gambiae s.l adults that were collected. Other sibling species of Anopheles gambiae s.l identified in the study site included An. arabiensis(3.6\%), and An. gambiae s.s. (8\%). The human blood index for An. merus was 0.12 , while the sporozoite rate was $0.3 \%$.

Conclusion: These findings suggest that An. merus can play a minor role in malaria transmission along the Kenyan Coast and should be a target for vector control which in turn could be applied in designing and implementing mosquito control programmes targeting marsh-breeding mosquitoes; with the ultimate goal being to reduce the transmission of malaria associated with these vectors.
\end{abstract}

\section{Background}

In Kenya, three members of the An. gambiae complex are responsible for malaria transmission including $A n$. gambiae s.s, An. arabiensis and An. merus [1-3]. The inability to morphologically distinguish between the three sibling species complicates the planning and maintenance of vector control activities in areas where these species co-occur $[4,5]$, because they differ in their ecology and behaviour and contribute asymmetrically to malaria transmission. Proper identification of these species in a particular region can pave way for meaningful studies on their breeding, oviposition, biting, resting and feeding behaviour all of which are essential for successful management of these species.

In the African continent, An. merus is exclusively confined to the Eastern coast stretching from South Africa to the horn of Africa [6]. Existing data suggests

\footnotetext{
*Correspondence: pamyabs@yahoo.com

${ }^{1}$ Kenya Medical Research Institute, Center for Geographic Medicine ResearchCoast, Kilifi, Kenya

${ }^{2}$ Moi University, Eldoret, Kenya
}

that this species is mainly zoophilic [7]. Analysis of blood meal sources from anopheline mosquitoes collected along the coast of Kenya showed that An. merus predominantly fed on humans, suggesting that this species was highly anthropophilic at the coast [8]. In Madagascar, [9], similar observations were recorded. This is in contrast to earlier studies [7] which showed that An. merus was mainly zoophilic, with a stronger tendency to bite more when outdoors than indoors. Peak biting activities of An. merus occur between 2400 hours and 0100 hours [7]. Previously An. merus was considered to play a minor role in malaria transmission [7], but recent studies in Madagascar and coastal parts of Tanzania have elevated the vector status of this species $[9,10]$.

However, no studies have been conducted to elucidate the extent of its efficiency as a vector including its breeding, resting and feeding behaviour. Along the Kenyan coast, there is no recent detailed information on the biology, behaviour and importance of this species as an important vector of malaria. The overall goal of the studies in this paper was to examine the ecology and

\section{Biomed Central}

(c) 2013 Kipyab et al.; licensee BioMed Central Ltd. This is an Open Access article distributed under the terms of the Creative Commons Attribution License (http://creativecommons.org/licenses/by/2.0), which permits unrestricted use, distribution, and reproduction in any medium, provided the original work is properly cited. 
behaviour of An. merus and its role in malaria parasite transmission in Garithe area of Malindi District along the Kenyan coast.

\section{Methods \\ Study site}

The study was carried out in Malindi district, which is the tenth largest town in Kenya and a major tourist destination in Kilifi County along the Kenya Coast. Malindi town is approximately $108 \mathrm{~km}$ north of Mombasa. Entomological sampling was carried out in Garithe village located 27 kilometres north of Malindi town in Kenya. Garithe has been previously described $[8,11]$. The coastal part of Garithe consists of mangrove trees and the area experiences high tides every month leaving pools of water during the low tides. These pools of salty water provide suitable habitats for An. merus breeding. The area also has numerous pockets of man-made ponds.

\section{Entomological sampling}

Mosquitoes were collected inside and outside selected homesteads. For indoor collection, mosquitoes were collected weekly in 16 randomly selected houses by use of pyrethrum spray collection method (PSC) [12]. The collections were conducted between $0700 \mathrm{hrs}$ and 1000 hrs from September 2007 to March 2008. Knockeddown mosquitoes were placed in petri-dishes and transported to the KEMRI laboratory for further analysis. Additionally, indoor biting mosquitoes were collected by use of CDC light traps placed inside houses set between $1800 \mathrm{~h}$ and $0600 \mathrm{~h}$. Ten traps were set inside 10 selected houses. Outdoor biting mosquitoes were collected by the use of CDC light traps with a lid hung outside five selected houses and cattle sheds.

\section{Laboratory processing of mosquitoes}

In the laboratory, female Anopheles were morphologically identified to species [13]. The legs of each Anopheles gambiae s.l. were detached from the rest of the body and used for sibling species identification using rDNA-PCR [4]. The heads and thorax were used for Plasmodium falciparum sporozoite Enzyme Linked Immunosorbent Assay (ELISA) [14]. The fully blood fed abdomens were tested for host sources of blood by ELISA [15]. Test samples were visually assessed for positivity [16].

\section{Entomological indices}

Entomological Inoculation rates (EIR), a standard measure of transmission intensity, is expressed as the number of infective bites per person per unit time (e.g., daily, monthly, yearly). The EIR was obtained by multiplying the human-biting rate by the proportion of sporozoite positive mosquitoes. The human blood index was determined as the proportion of blood-fed mosquitoes that had fed on humans out of the total number tested. The feeding success was determined as the proportion of blood fed and semi-gravid mosquitoes in the total proportion presumed to have been trying to feed (all mosquitoes except gravids) [17]. The sporozoite index for a given species was calculated as the proportion of females carrying infective sporozoites in the head-thorax. The human-biting rates (the number of biting mosquitoes per human-night), was calculated by dividing the total number of blood-fed and half-gravid mosquitoes caught in PSC catches by the number of persons sleeping in the house the night preceding the collection.

\section{Statistical analysis}

Fisher's analysis of variance was used to determine the resting and feeding behaviour of An. merus adults. The data was analysed by the use of SPSS for Windows (version. 15) (CDC Atlanta, USA).

\section{Ethical considerations}

This project involves very minimal interaction with human subjects; therefore no ethical approval was needed.

\section{Results}

An. gambiae s.l represented $96.8 \%$ of the total anophelines $(\mathrm{n}=400)$ collected during the six month sampling period. Other species included An. funestus (2.5\%) and An. coustani (0.8\%). The majority of $A n$. gambiae s.l (97.2\%) were collected during the short rains between September and December.

\section{Proportion of An. gambiae s.l adult sibling species found in Garithe}

Eighty nine percent (89\%) of the 387 An. gambiae samples tested by rDNA PCR were successfully identified to species. These comprised of An. merus (77.8\%), An. gambiae s.s (10.6\%) and An. arabiensis (8\%). This suggests that $A n$. merus is the predominant species in Garithe where it occurs in sympatry with An. arabiensis and An. gambiae s.s although they can occupy a different ecological niche (Figure 1).

\section{Blood meal identification and host seeking behaviour}

ELISA analysis of 83 blood fed An. merus high preference for animals as opposed to humans (Table 1). The blood meal analysis showed that a total of $31.7 \%$ (26) of the An. merus was shown to have fed on bovines, while $9.8 \%$ (9) fed on goats, $19.6 \%$ (16) was mixed feeding of bovine and goats only, $12.1 \%$ (10) fed on humans and $26.8 \%$ was unknown. Generally more blood fed An. merus were sampled indoors, 34\%, as compared to those sampled outdoors, $23 \%$. In indoor collection only $10.9 \%$ An. merus fed on humans, $24.4 \%$ fed on 


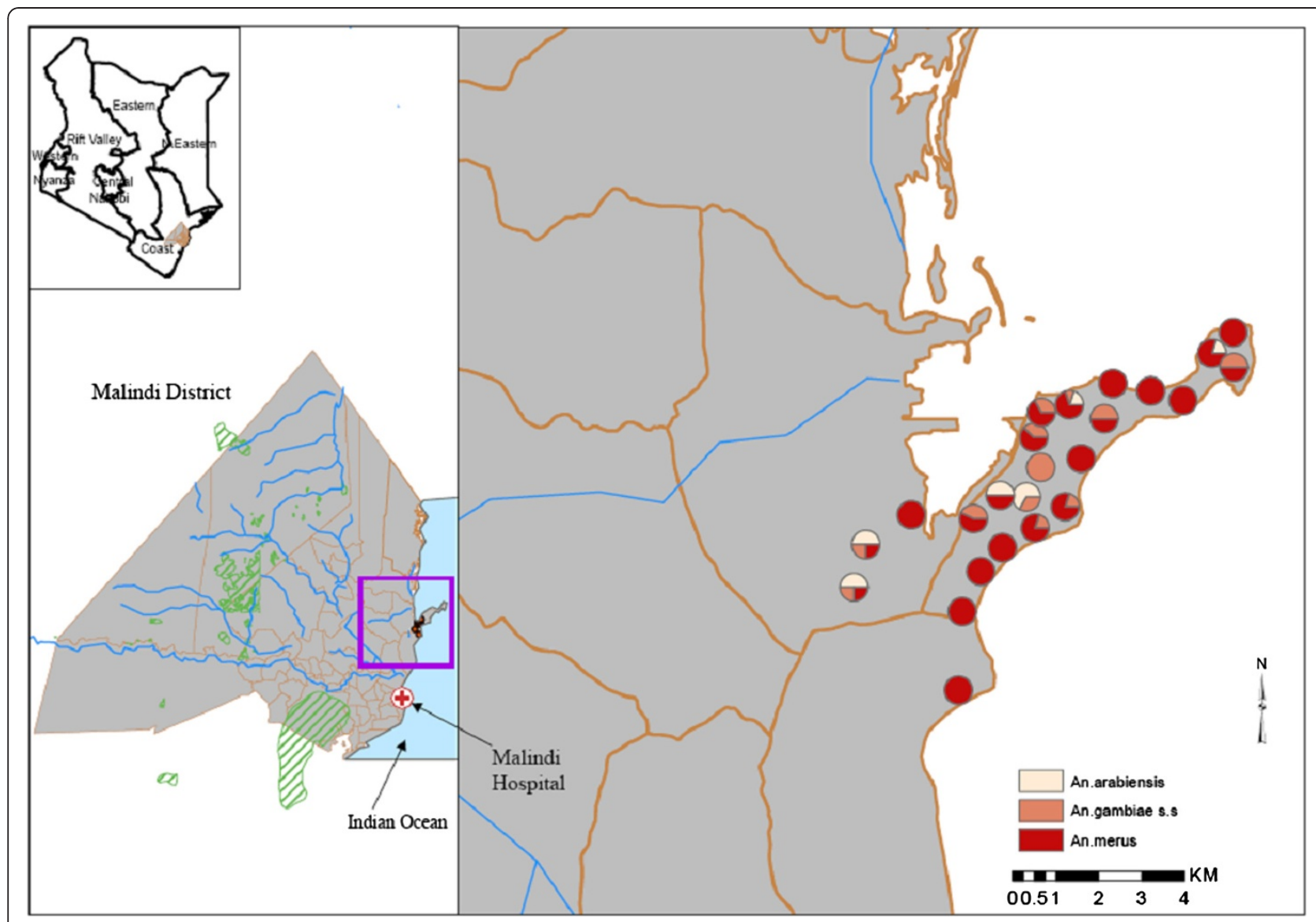

Figure 1 Map of Garithe showing distribution and proportion of An. merus, An. gambiae s.s and An. arabiensis. *the circles in the map represent the location (GPS coordinates) in which the Anopheles mosquitoes were collected.

Table 1 Bloodmeal sources for An. Merus collected indoors (PSC and Light traps placed indoors) and outdoors (light traps placed outdoors) in Garithe, Malindi District

\begin{tabular}{|c|c|c|c|c|c|c|c|}
\hline \multirow[b]{2}{*}{ Species } & \multirow[b]{2}{*}{ Collection } & \multirow[b]{2}{*}{ No. Tested } & \multicolumn{5}{|c|}{$\%$ of blood meal sources } \\
\hline & & & Human & Bovine & Goat/Bovine & Goat & Unknown \\
\hline \multirow[t]{2}{*}{ An. merus } & Indoors & 64 & 12.1 & 24.4 & 15.9 & 4.9 & 20.7 \\
\hline & Outdoors & 19 & 0 & 7.3 & 3.7 & 4.9 & 6.1 \\
\hline Total & & 83 & $12.1(10)$ & $31.7(26)$ & $19.6(16)$ & $9.8(9)$ & $26.8(22)$ \\
\hline \multirow[t]{2}{*}{ An. gambiae s.s } & Indoors & 2 & 0 & 16.6 & 16.6 & 16.7 & 16.7 \\
\hline & Outdoors & 4 & 0 & 0 & 0 & 16.7 & 16.7 \\
\hline Total & & 6 & $0(0)$ & $16.6(1)$ & $16.6(1)$ & $33.4(2)$ & $33.4(2)$ \\
\hline \multirow[t]{2}{*}{ An. arabiensis } & Indoors & 2 & 0 & 25 & 25 & 0 & 25 \\
\hline & Outdoors & 2 & 0 & 0 & 25 & 0 & 0 \\
\hline Total & & 4 & 0 & $25(1)$ & $50(2)$ & $0(0)$ & $25(1)$ \\
\hline \multirow[t]{2}{*}{ Unknown } & Indoors & 4 & 8.3 & 25 & 16.8 & 16.6 & 16.7 \\
\hline & Outdoors & 8 & 0 & 0 & 0 & 8.3 & 8.3 \\
\hline Total & & 12 & $8.3(1)$ & $25(3)$ & $16.8(2)$ & 24.9 (3) & $25(3)$ \\
\hline
\end{tabular}


bovine, $15.9 \%$ fed on goat/bovine, and $4.9 \%$ fed on goat while $20.7 \%$ fed on unknown blood meal sources. In outdoor collections, $1.2 \%$ fed on humans, $7.3 \%$ fed on bovine, $3.7 \%$ cross fed on goat/bovine and $4.9 \%$ fed on goat while $6.1 \%$ fed on other sources.

None of the An. gambiae s.s collected indoors were observed feeding on humans, but $16.7 \%$ fed on bovine, goat/bovine, goat and other hosts. Consequently, none of the outdoor An. gambiae mosquitoes fed on humans, bovine or goat/bovine. Among the An. arabiensis collected indoors, $25 \%$ of them fed only on both bovine and goat/bovine. There was no statistical significance in feeding behaviour and blood meal sources for An. merus on human and non-human blood meals (Fishers exact test, $\mathrm{P}=0.588$ ) suggesting that they can feed both indoors and outdoors and are not specific in the sources of blood meal.

Human biting rate, sporozoite rate and the Entomologic inoculation rate for An. merus

Table 2 shows the Plasmodium falciparum sporozoite rates for An. merus, An. gambiae s.s and An. Arabiensis obtained using a sporozoite ELISA method. The Plasmodium falciparum rate for An. merus in Garithe was $0.3 \%$. No infections were detected in the few An. gambiae s.s, and $A n$. arabiensis tested.

The mean monthly human biting rate (HBR) and mean monthly entomological inoculation rate (EIR) for An. merus for the period September 2007 to March 2008 is shown in Table 3 . The HBR for the six months ranged from 0.000 to 0.875 bites per person per month for the outdoor collections, while for the indoor collections it ranged from 0 to 1.606 bites per person per month. Overall, the HBR was highest in indoor collections during the month of September 2007 (1.606 bites per person per month), and lowest in the months of February 2008 and March 2008. The mean monthly EIR for the six month period ranged from undetectable levels to 0.018 infective bites per person. Overall, EIR for the six months was 0.003 infective bites per person both indoors and outdoors indicating that an individual would receive approximately 3 infective bites every 3 years.

\section{Discussion}

Abundance of An. merus species composition

$A n$. merus was the most abundant species sampled in Garithe, this could be because of the favourable larval

Table 2 Plasmodium falciparum sporozoites for An. merus, An. gambiae s.S, and An. arabiensis in Garithe, Malindi

\begin{tabular}{lcc}
\hline Species & No. tested & P. falciparum ELISA\% \\
\hline An. merus & $301(77.8 \%)$ & 0.3 \\
An. gambiae s.s & $31(8.0 \%)$ & $0(0)$ \\
An. Arabiensis & $14(3.6 \%)$ & $0(0)$ \\
\hline
\end{tabular}

Table 3 Monthly mean summary of HBR and EIR of An. merus in Garithe from September 2007 to March 2008 calculated using indoor collections and outdoor collections

\begin{tabular}{llccc}
\hline An. merus & Month & HBR & SR & EIR \\
\hline Outdoor collections $^{*}$ & September 2007 & 0.875 & 0.00 & 0.00 \\
& October 2007 & 0.466 & 0.00 & 0.00 \\
& November 2007 & 0.276 & 0.00 & 0.00 \\
& December 2007 & 0.303 & 0.30 & 0.018 \\
& January 2008 & - & - & - \\
& February 2008 & 0.00 & 0.00 & 0.00 \\
& March 2008 & 0.00 & 0.00 & 0.00 \\
Indoor collections & September 2007 & 1.606 & 0.00 & 0.00 \\
& October 2007 & 0.765 & 0.00 & 0.00 \\
& November 2007 & 0.421 & 0.00 & 0.00 \\
& December 2007 & 0.195 & 0.00 & 0.00 \\
& January 2008 & - & - & - \\
& February 2008 & 0.00 & 0.00 & 0.00 \\
& March 2008 & 0.00 & 0.00 & 0.00 \\
\hline
\end{tabular}

* was multiplied by a conversion factor of 1.605 and the $\mathrm{HBI}$.

HBR-Human biting rate, SR- Sporozoite rate, EIR- Entomologic inoculation rate.

habitats which are saline. Apart from being the abundant species it was found to exist in sympatry with other members of the An. gambiae complex, this shows that $A n$. merus can co-exist with other members of the complex. These findings are similar to earlier observations made [11], which found An. merus to be one of the sibling species along the Kenyan coast.

\section{Vector behaviour: resting, feeding and transmission potential}

There were significant differences in the number of $A n$. merus sampled indoors and outdoors, this shows that An. merus adults rested both indoors and outdoors; the findings of this paper contrasted with those reported in Jimbo valley where it was found that $A n$. merus rested mainly outdoors [18].

An. merus bites both indoors and outdoors and showed a tendency to feed on both human and nonhuman blood, most of the An. merus fed on bovine, goat or on mixed blood feeding on goat and bovine and humans suggesting that, An. merus is both zoophagic and anthropophagic. These findings were also observed in Jimbo Valley on the behavioural studies of An. merus on the Kenyan Coast [18]. From Results of the study were shown to differ from previous observations in Garithe, where it was observed that An. merus primarily fed on humans despite the availability of cows and goats $[8,19]$, this could have been because their data was based on only blood meal analysis performed on mosquitoes 
collected by light traps placed indoors, therefore targeting those that feed on humans $[8,19]$.

An. merus showed positivity for P. falciparum sporozoites with a percentage of 0.3 , these findings showed that $A n$. merus can transmit malaria parasites, as shown in studies carried out in Garithe, where the sporozoite rate of $A n$. merus was $2.41 \%$ [11]. This demonstrates that An. merus can play a minor but important role. In Tanzania An. merus plays an important role in malaria transmission, this was shown by a study in which An. merus had a sporozoite rate of $11.6 \%$ [10]. This was also the same in Madagascar, where the role of An. merus as a malaria vector was confirmed in the case of two human-biting females, which were ELISApositive for Plasmodium falciparum [9]. However, studies carried out on blood meal analysis for the Anopheline mosquitoes sampled along the Kenyan coast showed that there were no sporozoite infections found in the An. merus tested [8]. The low sporozoite rate of An. merus in Garithe could be attributed to its feeding largely on non-human blood (bovine, goat), which were abundant in every homestead sampled, this could be attributed to use of bed nets and screened windows.

\section{Risk of transmission}

The extent of the entomologic inoculation rate is influenced by the rate at which vectors feed on humans and the sporozoite rate. In Garithe, the HBR generally was low and did not exceed previous findings in Garithe where the HBR was 2.45 infective bites per day [8], but in this study it was observed that the HBR averaged to 0.49 infective bites per day both indoors and outdoors, this in turn reduced the EIR.

Overall, the results of this study revealed the EIR for the six months was 0.003 infective bites per person both indoors and outdoors indicating that an individual would receive approximately 3 infective bites every 3 years. Thus the transmission potential for An. merus in Garithe was very low as compared to previous studies, [11]. These observations show that malaria transmission by An. merus has decreased, however, it should be taken into consideration that, it can be a significant vector at specific times of the year and that relatively high malaria parasite prevalence can occur at low or even below detectable levels of transmission $[11,19,20]$.

\section{Conclusion}

In conclusion, this study has shown that An. merus is the abundant species found in Garithe; this species can feed on human and non human blood, bite and rest both indoors and outdoors and have the potential to spread malaria albeit at low rates. These evidence-based findings on its resting, feeding and transmission potential will be useful for the planning of control strategies for malaria vectors.

\section{Competing interests}

The authors declare that they have no competing interests.

\section{Authors' contributions}

PCK, BK, CM and JM conceived and planned the study, interpreted results and wrote the paper. PCK directed and performed the field and laboratory experiments, CM facilitated field and laboratory experiments by selecting study sites, JM assisted in obtaining local clearance from community leaders and also performed statistical analysis. All authors read and approved the final manuscript.

\section{Acknowledgements}

The study was funded by KEMRI. We are grateful to Mr. Joseph Nzovu for the technical support in the laboratory. Festus Yaa, David Shida, Gabriel Nzai and Hesbon Njue for their technical support in the field. We thank the people of Garithe and the KEMRI Malindi team for their co-operation and support.

Received: 21 November 2012 Accepted: 1 February 2013

Published: 14 February 2013

\section{References}

1. Mbogo CM, Mwangangi JM, Nzovu J, Gu W, Yan G, Gunter JT, Swalm C, Keating J, Regens JL, Shililu Jl: Spatial and temporal heterogeneity of Anopheles mosquitoes and Plasmodium falciparum transmission along the Kenyan coast. Am J Trop Med Hyg 2003, 68:734-742.

2. Mbogo CNM, Baya NM, Ofulla AVO, Githure Jl, Snow RW: The impact of permethrin- impregnated bed nets on malaria vectors of the Kenyan coast. Med Vet Entomol 1996, 10:251-259.

3. Petrarca $\vee$, Beier JC: Interspecific chromosomal polymorphism in the Anopheles gambiae complex as a factor affecting malaria transmission in the Kisumu area of Kenya. Am J Trop Med Hyg 1992, 46:229-237.

4. Scott JA, Brodgon WG, Collins FH: Identification of single specimens of Anopheles gambiae complex by Polymerase chain reaction. Am J Trop Med Hyg 1993, 49:520-529.

5. Service MW: Mosquito Ecology: Field Sampling Methods. Second Edition. London and New York: Elsevier Applied Science; 1993.

6. Sattler MA, Mtasiwa D, Kiama M, Premji Z, Tanner M, Killeen GF, Lengeler C: Habitat characterization and spatial distribution of Anopheles sp. mosquito larvae in Dar es Salaam (Tanzania) during an extended dry period. Malaria J 2005, 4:4

7. Mutero CM, Mosha F, Subra R: Biting activity and resting behaviour of Anopheles merus Donitz (Diptera: Culicidae) on the Kenyan Coast. Ann Trop Med Parasit 1984, 78:43-47.

8. Mwangangi JM, Mbogo CM, Nzovu JG, Githure JI, Yan G, Beier JC: Blood meal analysis for anopheline mosquitoes sampled along the Kenyan coast. J Am Mosq Control Assoc 2003, 19:371-375.

9. Pock TJM, Duchemin JB, Marrama L, Rabarison P, Le Goff G, Rajaonarivelo V, Roberts V: Distribution of the species of Anopheles gambiae complex and first evidence of Anopheles merus as a malaria vector in Madagascar. Malaria J 2003, 2:33.

10. Temu EA, Minjas JN, Coetzee M, Hunt RH, Shiff CJ: The role of four anopheline species (Diptera: Culicidae) in malaria transmission in coastal Tanzania. Trans R Soc Trop Med Hyg 1998, 92:152-158.

11. Mbogo CM, Mwangangi JM, Nzovu J, Gu W, Yan G, Gunter J, Swalm C, Keating J, Regens JL, Shililu Jl, et al: Spatial and temporal heterogeneity of Anopheles mosquitoes and Plasmodium falciparum transmission along the Kenyan coast. Am J Trop Med Hyg 2003, 68:734-742.

12. WHO: Manual on practical entomology in Malaria. Part II. Methods and techniques. Geneva: World Health Organization Offset Publication; 1975:No. 13

13. Gillies MT, Coetzee M: A supplement to Anophelinae of Africa south of Sahara (Afro-tropical region). Pub/ S Afr Inst Med Res 1987, 55:1-143.

14. Beier JC, Perkins PV, Wirtz RA, Whitmire RE, Mugambi M, Hockmeyer WT: Field evaluation of an enzyme-linked immunosorbent assay (ELISA) for Plasmodium falciparum sporozoite detection in anopheline mosquitoes from Kenya. Am J Trop Med Hyg 1987, 36:459-468.

15. Beier JC, Asiago CM, Onyango FK, Koros JK: ELISA absorbance cut-off method affects malaria sporozoite rate determination in wild Afrotropical Anopheles. Med Vet Entomol 1988, 2:259-264. 
16. Beier JC, Koros J: Visual assessment of sporozoite and blood meal ELISA samples in malaria field studies. J Med Entomol 1991, 28:805-808.

17. Charlwood JD, Kihonda J, Sama S, Billingsley PF, Hadji H, Verhave JP, Lyimo E, Luttikhuizen PC, Smith T: The rise and fall of Anopheles arabiensis (Diptera: Culicidae) in a Tanzanian village. Bull Entomol Res 1995, 85:37-44.

18. Mosha FW, Petraca V: Ecological studies on Anopheles gambiae complex on the Kenya coast. Trans R Soc Trop Med Hyg 1983, 77:344-345.

19. Mbogo CNM, Kabiru EW, Muiruri SK, Nzovu JM, Ouma JH, Githure Jl, Beier JC: Bloodfeeding behaviour of Anopheles gambiae s.l. and Anopheles funestus in Kilifi district, Kenya. J Am Mosa Control Assoc 1993, 9:225-227.

20. Beier JC, Killeen G, Githure Jl: Short report: entomologic inocululation rates and Plasmodium falciparum malaria prevalence in Africa. Am J Trop Med Hyg 1999, 61:109-113.

doi:10.1186/1756-3305-6-37

Cite this article as: Kipyab et al.: The bionomics of Anopheles merus

(Diptera: Culicidae) along the Kenyan coast. Parasites \& Vectors 2013 6:37.

\section{Submit your next manuscript to BioMed Central and take full advantage of:}

- Convenient online submission

- Thorough peer review

- No space constraints or color figure charges

- Immediate publication on acceptance

- Inclusion in PubMed, CAS, Scopus and Google Scholar

- Research which is freely available for redistribution 